\title{
Does Religion/Spirituality Modify the Association of Stressful Life Events and Suicidal Ideation in Australian Men?
}

\author{
Karolina Krysinska ${ }^{1,2, *}$, Matthew J. Spittal ${ }^{1}$, Jane Pirkis ${ }^{1}$ and Dianne Currier ${ }^{1}$ \\ 1 Centre for Mental Health, Melbourne School of Population and Global Health, The University of Melbourne, \\ VIC 3010, Australia; m.spittal@unimelb.edu.au (M.J.S.); j.pirkis@unimelb.edu.au (J.P.); \\ dianne.currier@unimelb.edu.au (D.C.) \\ 2 Centre for Primary Health Care and Equity, University of New South Wales, Sydney NSW 2052, Australia \\ * Correspondence: karolina.krysinska@unimelb.edu.au; Tel.: +31-03-990-300-22
}

Received: 15 March 2018; Accepted: 17 May 2018; Published: 3 June 2018

\begin{abstract}
In a large population cohort of Australian men, we previously observed that stressful life events were associated with increased suicidal ideation (SI). Many stressful life events, such as relationship breakdown and financial difficulties, occur frequently, yet most men who experience them do not have suicidal thoughts. There is some evidence that religious belief may be protective against suicidal behaviour. This study examined if attendance of religious service and/or perceived importance of religion/spirituality to participants modifies the association between stressful life events and suicidal thinking. Our analysis included 10,588 men who were aged 18 years or older who participated in the Australian Longitudinal Study on Male Health (Ten to Men), a national cohort study of Australian males. The study compared demographic, protective and risk factors for four subgroups: No SI, Remitted SI, New SI, and Chronic SI between Wave 1 (October 2013 to July 2014) and Wave 2 (November 2015 to May 2016) of the study and conducted logistic regression for these four outcomes. The study found a protective effect for attendance of religious services for the onset of New SI at Wave 2. Importance of religion/spirituality was positively related to Chronic SI. There were no effects of service attendance or importance for any of the other SI outcomes. We discuss results of the study in relation to social connection and broader contextual factors, such as secularization.
\end{abstract}

Keywords: suicidal ideation; males; longitudinal study; protective factors; religiosity; spirituality

\section{Introduction}

Religion and spirituality are recognized as potentially protective factors against suicidal ideation (SI) and behaviour. About three quarters of studies published to-date reported a significant inverse relationship between at least one aspect of religion and at least one dimension of suicidality (Koenig et al. 2012; Stack and Kposowa 2011). A recent meta-analysis, including case-control and retrospective cohorts, found an overall protective effect of religiosity against suicide (Wu et al. 2015), and attendance at religious services was found to be protective against suicide in two major US-based general population studies (Kleiman and Liu 2014; Nisbet et al. 2000). The salutary effect of religion and spirituality may be related to the protective effect of religious social networks and social support and/or hope, against stressful life events created by religious beliefs, such as a belief in an afterlife (Lawrence et al. 2016a; Stack and Kposowa 2011).

In a large population cohort of Australian men we previously observed that stressful life events were associated with increased suicidal thinking (Currier et al. 2016). Suicidal ideation and behaviour occur frequently among Australian males. Ten to Men, Australian longitudinal study on male health, reported $18.6 \%$ lifetime prevalence of suicidal ideation among Australian males and $5.4 \%$ lifetime 
prevalence of suicide attempts (Currier et al. 2016). This occurs in a setting where, in 2016, 2151 of the total number of 2866 suicides in Australia were males, and the standardised male suicide rate was 1.5 times higher than the national rate (17.8 per 100,000 and 11.8 per 100,000, respectively) (ABS 2017a).

Some of the risk factors for suicide, such as a history of hospitalized mental illness, are plausibly equally relevant for both genders (Qin et al. 2000). Other factors may relate particularly to males (Pitman et al. 2012). Shiner et al. (2009) reported that work-related problems, such as redundancy and unemployment, financial problems, and criminal behaviour, are related to suicide in middle-age males. In regards to suicidal ideation, interpersonal difficulties (Liu and Miller 2014) and affective disorders (Nock et al. 2008) are often related to thoughts of suicide, although there is sparse research specifically in relation to males (Nock et al. 2008; Smith et al. 2016). On the other hand, social connection and support, resilience, purpose in life, gratitude, and optimism may protect males against thoughts of suicide (Smith et al. 2016).

There is evidence that religion and spirituality may be protective against suicidal behaviour and ideation in general. However, there is a lack of studies specifically in males. A recent systematic review (Lawrence et al. 2016a) reported on complex links between various dimensions of religion, including service attendance, and different aspects of suicidality, including suicidal ideation; nonetheless, it did not include an analysis gender-specific effects. Similarly, Nishi et al. (2017) looked at the association between personal importance of religion, service attendance, and suicide ideation in a general population survey; however, the study did not analyse associations with gender. Although the protective effect of religiosity appears to be weaker in males than in females (Kelleher et al. 1998; Kralovec et al. 2017), there is some evidence that male gender may moderate the relationship between religiosity and suicidality on an individual (Sharma et al. 2017) and/or ecological level (Neeleman et al. 1997; Neeleman and Lewis 1999).

Many risk factors, including stressful life events, occur frequently, yet most men who experience them do not have suicidal thoughts (Currier et al. 2016). This study examines if attendance of religious service and/or perceived importance of religion/spirituality to participants modifies the association between stressful life events and suicidal thinking in Australian males. In particular, we explore whether these two variables are related to remission, onset, and/or chronic suicidal ideation after adjusting for sociodemographic factors and considering a range of psychosocial risk and protective factors as covariates, assessed over two Waves of a longitudinal study.

\section{Methods}

The Australian Longitudinal Study on Male Health (Ten to Men) is a national cohort study of Australian males aged 10-55 years at recruitment (Pirkis et al. 2013). Recruitment and Wave 1 data collection was completed between October 2013 and July 2014 and achieved an overall response fraction of $36 \%$ (Currier et al. 2016). In total, 16,021 males aged 10-55 years participated in Wave 1 . Wave 2 was conducted two years later, between November 2015 and May 2016 with $76 \%$ of the cohort participating. This analysis includes 10,588 men who were aged 18 years or older at Wave 1 who also participated in Wave 2 (Figure 1). 


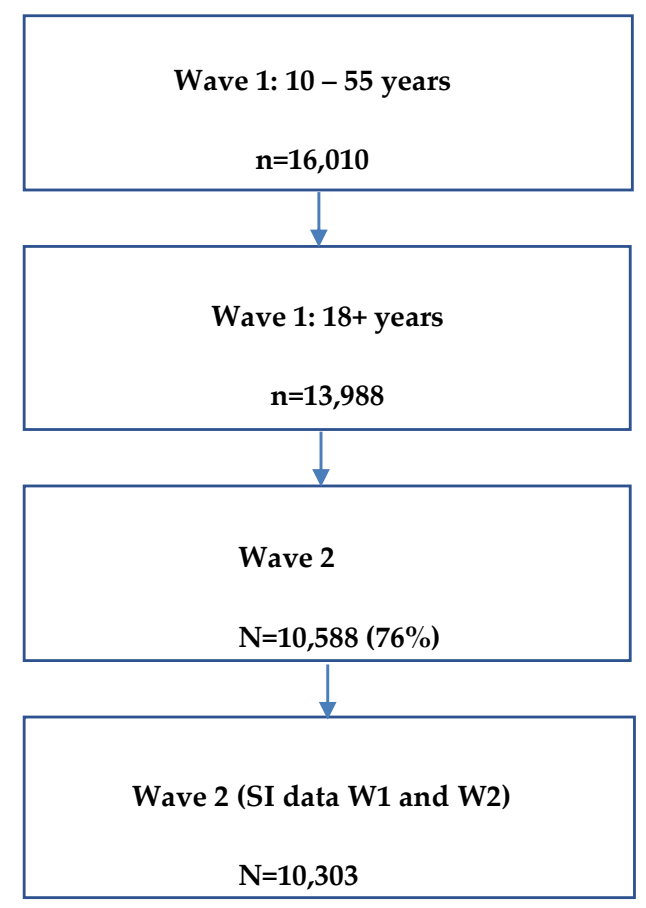

Figure 1. Flowchart of study participants, Wave 1 and Wave 2.

A stratified, multi-stage cluster sampling design was used and participants were recruited via household recruitment. Self-complete paper questionnaires collected information on a broad range of health and lifestyle factors. Full details of sample design, recruitment and data collection methods are available elsewhere (Currier et al. 2016). Ethics approval was obtained from the University of Melbourne Human Research Ethics Committee. All participants provided written informed consent.

\section{Measures}

\subsection{Outcome-Suicidal Ideation}

Suicidal ideation in the past two weeks at Wave 1 and at Wave 2 was ascertained using the item 'Thoughts that you would be better off dead or of hurting yourself in some way' from the Patient Health Questionnaire (PHQ-9) (Kroenke et al. 2001). Respondents indicate the frequency of such thoughts in the past two weeks as 'not at all', 'several days', 'more than half the days', and 'nearly every day'. Binary variables were created for Wave 1 current suicidal ideation and Wave 2 current suicidal ideation where 'not at all' was coded ' $\mathrm{No}^{\prime}$ and any other response was coded 'Yes'. Following Smith et al. (2016) we then constructed four subgroups based on suicidal ideation status (1) nNo suicidal ideation —negative for suicidal ideation at both Waves; (2) Remitted suicidal ideation-positive for suicidal ideation at Wave 1, but negative at Wave 2; (3) New suicidal ideation-negative for suicidal ideation at Wave 1, but positive at Wave 2, and; (4) Chronic suicidal ideation-positive for suicidal ideation at both Wave 1 and Wave 2 .

\subsection{Exposures}

Three protective factors were included-frequency of attendance at religious services, importance of religion/spirituality, and social support. Attendance of religious services was assessed with a single question: 'How often do you attend religious services (such as going to church, temple, mosque, or other religious institutions or activities)?' Response options were 'never', 'about once or twice a year', 'about once every few months', 'about once or twice a month', and 'about once a week or more'. Due to small numbers in some of the response options, we derived a variable with three response 
categories: 'never', 'less than weekly', and 'weekly or more'. The importance of religion/spirituality was assessed by the questions 'How important is religion or spirituality in your life?' with response options of 'extremely important', 'very important', 'somewhat important', 'not very important', and 'not important at all'. Again, we derived a variable with three response categories: 'not important at all', 'somewhat or not very important', and 'very or extremely important' to allow for a more meaningful statistical analysis. Previous studies (Kleiman and Liu 2014; Rasic et al. 2009) used similar single item measures.

Social support at Wave 1 was rated using the emotional/informational support scale from the Medical Outcomes Study-Social Support Scale (MOS-SSS) (Tarlov et al. 1989). The MOS-SSS includes eight questions asking participants how often particular elements of emotional/informational support are available to them, including having someone to give good advice in times of crisis and having someone to confide in. Respondents' answer choices include 'none of the time' (score 1), 'a little of the time', 'some of the time', 'most of the time', and 'all of the time' (score 5). Scores across all eight questions are averaged, with a higher average score indicating the presence of perceived greater emotional/informational social support. Cronbach's alpha for MOS-SSS in our study was 0.97.

Two risk factors were included, lifetime depression and experiencing a negative life event. Lifetime depression at Wave 1 was ascertained by the question: 'Have you been treated for or had any symptoms of this condition in the past 12 months?' with depression as a response option. This format for capturing self-reported long-term conditions was based on the Australian Health Survey (ABS 2013). Life events in the 12 months prior to Wave 1 were ascertained using a 24 item life events checklist based on items from the Social Readjustment Scale (Holmes and Rahe 1967). From the list of 24 we included six life events we have previously found associated with suicidal ideation (Serious personal injury, Relationship end, Family conflict, Difficulty finding work, Legal troubles, Loss of personal property) (Currier et al. forthcoming). We created a binary variable with 'no life events' /'at least one life event'. Participant sociodemographics included were age, marital status (married or de facto/not married or de facto), high school completion (yes/no), and region of residence (major city/inner regional/ outer regional).

\section{Statistical Analyses}

We compared demographic, protective factors and risk factors for the four groups: No SI, Remitted SI, New SI, and Chronic SI using chi-square for categorical variables and ANOVA for age as a continuous variable. We then ran logistic regression for each of the following outcomes: No SI vs. Remitted SI, No SI vs. New SI, No SI vs. Chronic SI, and Remitted vs. Chronic SI. Covariates in each model were W1 lifetime depression, life event, religious service attendance, importance of religion and spirituality, and MOSS social support score. Models were adjusted for demographic variables that differed significantly in group comparisons. All analyses were conducted using Stata 14.2.

\section{Results}

Table 1 shows group comparisons. Age, marital status and high school completion differed across the four groups. In general, participants with No SI and participants with Chronic SI at Wave 2 were older ( $M=39.3$ and $M=39.7$; respectively) than participants in the other two groups $(M=38.2$ and $M=37.8$ for Remitted SI and SI onset, respectively). Participants with No SI were more often married $(73.1 \%)$ and more often completed Year 12 education $(62.7 \%)$ than participants with Remitted SI, Chronic SI, and SI Onset at Wave 2 (married range 50.8\% to $63.4 \%$; year 12 range $50.7 \%$ to $58 \%$ ). There were also differences in regards to two of the risk factors examined in the study. Participants with No SI at Wave 2 less frequently reported lifetime depression (16.5\%) and major life events in the past 12 months (36\%) than participants with Remitted SI (46.4\% and 61.3\%), SI Onset at Wave 2 (35.4\% and 51\%) and Chronic SI (66.1\% and 70.5\%). There were also differences in regards to social support, frequency of service attendance and importance of religion and spirituality. For instance, 
participants in the No SI at Wave 2 group had the highest MOS-SSS score $(M=72.5)$ while those in the Chronic SI group had the lowest MOS-SSS score $(M=48.7)$.

Table 2 shows results of multivariable analyses. Adjusting for age, marital status and high school completion, lifetime depression at Wave 1, experiencing a major life event in the past 12 months and level of social support at Wave 1, attendance at religious services resulted in a reduction in the odds of experiencing new onset suicidal ideation at Wave 2. Relative to the odds for respondents who never attend religious services, there was a 32\% reduction in odds of new onset suicidal ideation for less than weekly attendance and a $48 \%$ reduction for weekly or more frequent attendance. Service attendance was not associated with any other suicidal ideation outcome. Importance of religion/spirituality was positively associated with Chronic SI: study participants who reported that religion/spirituality was 'extremely important' to them had 1.69 increased odds of having Chronic SI compared to No SI. There were no statistically significant effects for other SI outcomes.

Table 1. Group comparisons.

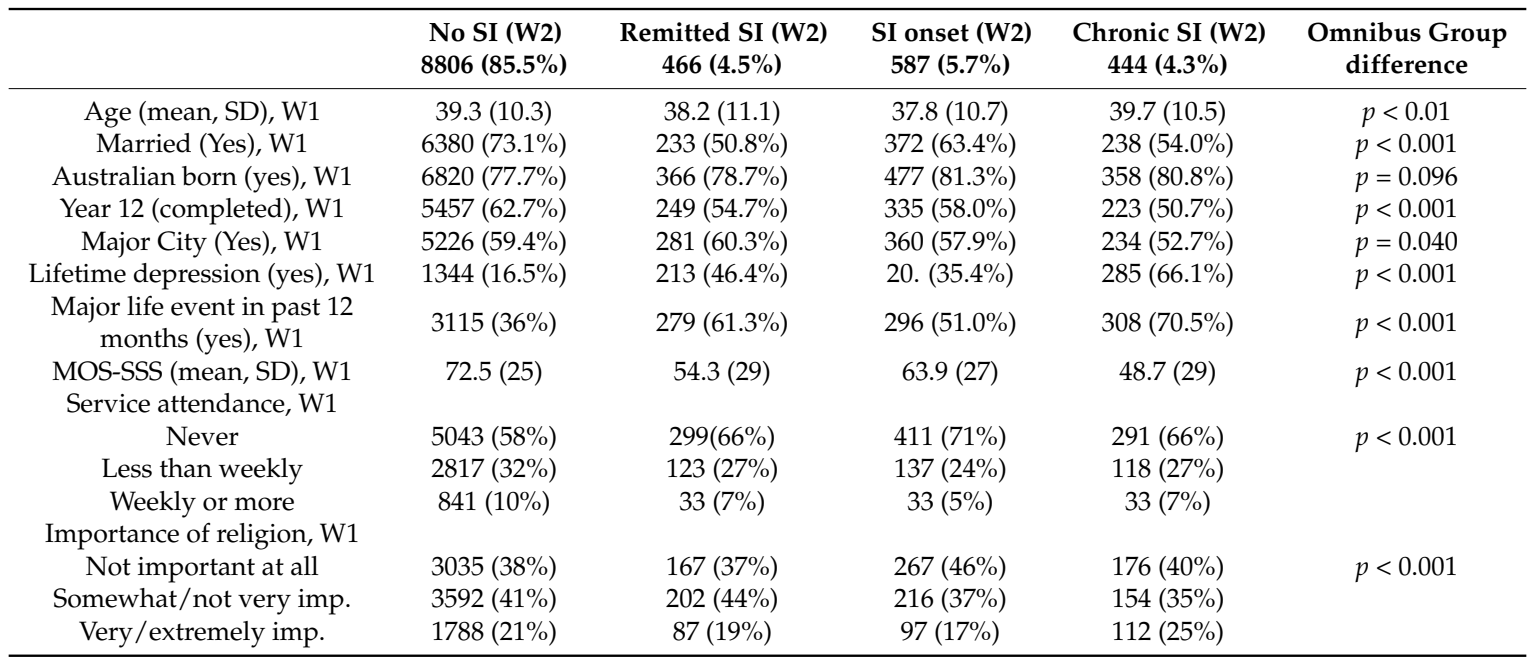

Table 2. Logistic regression models.

\begin{tabular}{|c|c|c|c|c|}
\hline & $\begin{array}{l}\text { Remitted SI } \\
\text { vs. No SI }\end{array}$ & $\begin{array}{l}\text { SI onset } \\
\text { vs. No SI }\end{array}$ & $\begin{array}{l}\text { Chronic SI } \\
\text { vs. No SI }\end{array}$ & $\begin{array}{l}\text { Remitted SI } \\
\text { vs. Chronic SI }\end{array}$ \\
\hline Risk Factors & OR $(95 \% \mathrm{CI}), p$ & OR $(95 \% \mathrm{CI}), p$ & OR $(95 \% \mathrm{CI}), p$ & OR $(95 \% \mathrm{CI}), p$ \\
\hline Lifetime Depression (W1) & $\begin{array}{c}3.84(3.11-4.73) \\
\quad p<0.001\end{array}$ & $\begin{array}{c}2.69(2.22-3.26) \\
p<0.001\end{array}$ & $\begin{array}{c}7.70(6.16-9.62) \\
p<0.001\end{array}$ & $\begin{array}{c}2.0(1.50-2.67) \\
\quad p<0.001\end{array}$ \\
\hline $\begin{array}{c}\text { Major Life Event in past } 12 \\
\text { months (W1) }\end{array}$ & $\begin{array}{c}1.73(1.40-2.14) \\
p<0.001\end{array}$ & $\begin{array}{c}1.46(1.22-1.75) \\
p<0.001\end{array}$ & $\begin{array}{c}2.41(1.91-3.04) \\
p<0.001\end{array}$ & $\begin{array}{c}1.39(1.03-1.87) \\
p=0.029\end{array}$ \\
\hline \multicolumn{5}{|l|}{ Protective Factors } \\
\hline \multicolumn{5}{|l|}{ Religious Attendance, W1 } \\
\hline Never & Ref & & & \\
\hline Less than weekly & $\begin{array}{c}0.83(0.64-1.07) \\
\quad p=0.153\end{array}$ & $\begin{array}{c}0.68(0.54-0.86) \\
\quad p=0.002\end{array}$ & $\begin{array}{c}0.83(0.63-1.10) \\
\quad p=0.196\end{array}$ & $\begin{array}{c}1.00(0.70-1.43) \\
p=0.984\end{array}$ \\
\hline Weekly or more & $\begin{array}{c}0.74(0.46-1.21) \\
\quad p=0.242\end{array}$ & $\begin{array}{l}0.52(0.33-0.82) \\
\quad p=0.005\end{array}$ & $\begin{array}{c}0.67(0.41-1.09) \\
\quad p=0.106\end{array}$ & $\begin{array}{c}0.89(0.47-1.69), \\
\quad p=0.722\end{array}$ \\
\hline \multicolumn{5}{|l|}{ Importance of relig/spirituality, W1 } \\
\hline Not important at all & Ref & & & \\
\hline Somewhat/not very important & $\begin{array}{c}1.23(0.97-1.56) \\
p=0.092\end{array}$ & $\begin{array}{c}0.87(0.70-1.06) \\
\quad p=0.157\end{array}$ & $\begin{array}{c}0.89(0.69-1.17) \\
p=0.423\end{array}$ & $\begin{array}{c}0.73(0.53-1.02), \\
\quad p=0.062\end{array}$ \\
\hline Very/extremely important & $\begin{array}{c}1.37(0.96-1.95), \\
p=0.086\end{array}$ & $\begin{array}{c}1.07(0.78-1.48) \\
p=0.679\end{array}$ & $\begin{array}{c}1.69(1.19-2.40) \\
p=0.003\end{array}$ & $\begin{array}{c}1.24(0.78-1.96) \\
p=0.364\end{array}$ \\
\hline Social Support, W1 & & & & \\
\hline
\end{tabular}


Table 2. Cont.

\begin{tabular}{ccccc}
\hline & $\begin{array}{c}\text { Remitted SI } \\
\text { vs. No SI }\end{array}$ & $\begin{array}{c}\text { SI onset } \\
\text { vs. No SI }\end{array}$ & $\begin{array}{c}\text { Chronic SI } \\
\text { vs. No SI }\end{array}$ & $\begin{array}{c}\text { Remitted SI } \\
\text { vs. Chronic SI }\end{array}$ \\
\hline Wave 1 MOS-SSS & $\begin{array}{c}0.978 \\
(0.975-0.997),\end{array}$ & $\begin{array}{c}0.988(0.985-0.99), \\
p<0.001\end{array}$ & $\begin{array}{c}0.973(0.970-978), \\
p<0.001\end{array}$ & $\begin{array}{c}0.995(0.991-1.00), \\
p=0.059\end{array}$ \\
& $p=0.013$ & & &
\end{tabular}

All analysis adjusted for age, marital status, and year12 completion. MOS-SSS: Medical Outcomes Study-Social Support Scale.

\section{Discussion}

This study examined whether religiosity operationalised as self-reported religious service attendance and perceived importance of religion/spirituality modified the association between stressful life events and thoughts of suicide in a representative sample of Australian males. Our findings were mixed. We found a protective effect for attendance of religious services for the onset of new SI at Wave 2 and a positive association between high importance of religion/spirituality and chronic SI outcome. There were no effects of service attendance or importance of religion/spirituality for other outcomes in the study sample.

It has been suggested that one of the mechanisms through which religious affiliation and participation is protective against suicidality is in providing social connection. In this study of Australian men, we found that while increased social support was associated with a reduced likelihood of SI, attendance of religious services remained independently associated with reduced likelihood of new onset suicidal ideation. This suggests that there may be other aspects of religious service attendance, beyond social support, that are protective against SI. It should be noted that we used only the emotional/information subscale of the MOSS, and potentially attending religious services provides different types of social support not assessed including tangible support or positive social interaction. Alternatively, participation in religious services may be a proxy for resilience, purpose in life, gratitude, and optimism (Smith et al. 2016), all of which may help men better cope with stressful life events and lower the likelihood of responding with suicidal ideation. Our study also suggests that for reasons we are not able to explain based on the current body of research evidence, this protective mechanism may not be effective in case of remission or coping with chronic SI in males.

Our result showing that males for whom religion/spirituality was 'extremely important' had increased odds of having chronic SI compared to no SI seems to run counter to the dictum that religion/spirituality protect against suicidality. Nonetheless, according to Lawrence et al. (2016a, 2016b), aspects of religiosity, such as affiliation and service attendance, may protect against suicide attempt but not necessarily against suicidal ideation. For instance, religious or spiritual beliefs may prevent some at-risk individuals from acting out their suicidal tendencies. Alternatively, deeply religious individuals may use negative religious coping strategies (Pargament et al. 2000) or experience spiritual struggles, such as a troubled relationship with God, stressful encounters with other believers, or self-questioning of religious beliefs (Exline and Rose 2005). Both can contribute to psychological distress (Ellison and Lee 2010) and suicidal ideation (Lawrence et al. 2016b). It is plausible that this phenomenon was observed in the Chronic SI subgroup in our study.

In general, results of the study may reflect the effects of progressing secularisation of Australia, where in 2016, 30\% of individuals reported having no religion (an increase by $8 \%$ since 2011) (ABS 2017b). Also, Australian males were more likely to report having no religion than Australian females (32\% vs. 28\%) (ABS 2017b). Studies conducted in other countries, such as Ireland (O'Reilly and Rosato 2015), show that the protective effect of religion observed by Durkheim (Durkheim [1897] 1951) may be declining with increasing levels of secularisation. In addition, association between religion and attitudes toward suicide and suicide risk in males seems to be more dependent upon broad contextual factors, such as the salience of religion in social environment and socio-economic conditions, than in females (Neeleman et al. 1997; Neeleman and Lewis 1999). In other 
words, it is possible that in a secularised social context, personal religious practices, such as religious service attendance, and personal importance of religion/spirituality may not protect males against suicidal ideation.

The limitations of current study might have affected reported results. The outcome measure of suicidal ideation was drawn from a composite scale designed to assess depression rather than from a suicide assessment instrument and, as such, may lack specificity. There are potential problems with reliability of recall of past life events related to the use self-report checklists to assess life events (Paykel 1983). Additionally, this study focused on proximal life stressors (past 12 months) as putative 'triggers' to current suicidal ideation. However, it is likely that for some individuals early-life stressors contribute to the association between religiosity, suicidal thoughts, and life events reported here, and that analyses examining both distal and proximal stressors are required to fully elucidate this relationship. The study looked at two self-reported measures of religion/spirituality, i.e., religious service attendance and perceived importance. These measures of religiosity were based on a single item, particularly perceived importance of religion, potentially relating to low reliability affecting study results. Religiosity is a multidimensional phenomenon, and its other aspects, such as religious affiliation or religious coping (Currier et al. 2017), may more strongly moderate the complex relationship between stressful life events and thoughts of suicide (Lawrence et al. 2016b). In addition, we were not able to disentangle the perceived importance of religion in relation to the perceived importance of spirituality. Religion and spirituality are two overlapping yet different phenomena (Streib and Klein 2016), each with potentially specific (protective) effects against suicidal ideation (Colucci and Martin 2008).

\section{Conclusions}

Results of the current study evidence the complex relationship between religion/spirituality and suicidal ideation. Attendance at religious services resulted in a reduction in the odds of new onset suicidal ideation in a representative sample of Australian males. In the same population, high importance of religion/spirituality was related to higher odds of chronic suicidal ideation. Nonetheless, we found no association between attendance and remitted or chronic suicidal ideation, and self-reported importance of religion/spirituality did not relate to remitted or new onset SI outcomes in the study sample. Future studies could explore aspects of religiosity, which were outside the scope of the study, which could be protective against SI or increase risk of SI in the context of broader socio-cultural processes, such as secularisation.

Author Contributions: All authors were responsible for the analytical design and were involved in interpreting the analysis. D.K. and M.S. undertook data analysis. K.K. and D.C. drafted the manuscript. All authors undertook critical revision of the manuscript and have approved this manuscript version for submission.

Acknowledgments: The research on which this paper is based was conducted as part of the Australian Longitudinal Study on Male Health (Ten to Men). We are grateful to the Australian Government Department of Health for funding and to the boys and men who provided the survey data. Ten to Men is managed by the University of Melbourne. Ten to Men data are the intellectual property of the Commonwealth.

Conflicts of Interest: The authors declare no conflicts of interest.

\section{References}

Australian Bureau of Statistics. 2013. Australian Health Survey: Users' Guide, 2011-2013, 2013 ed.; Canberra: ABS. Australian Bureau of Statistics. 2017a. 3303.0 Causes of Death, Australia, 2016; Canberra: ABS.

Australian Bureau of Statistics. 2017b. 2071.0 Religion in Australia. 2016 Census of Population and Housing; Canberra: ABS.

Colucci, Erminia, and Graham Martin. 2008. Religion and spirituality along the suicidal path. Suicide and Life-Threatening Behavior 38: 229-44. [CrossRef] [PubMed] 
Currier, Dianne, Matthew J. Spittal, George Patton, and Jane Pirkis. forthcoming. Life stress and suicidal ideation in Australian men-Cross-sectional analysis of the Australian Longitudinal Study on Male Health baseline data. BMC Public Health. [CrossRef] [PubMed]

Currier, Dianne, Jane Pirkis, John Carlin, Louisa Degenhardt, Shyamali C. Dharmage, Billie Giles-Corti, Ian Gordon, Lyle Gurrin, Jane Hocking, Anne Kavanagh, and et al. 2016. The Australian longitudinal study on male health-Methods. BMC Public Health 16: 6-13. [CrossRef] [PubMed]

Currier, Joseph M., Phillip N. Smith, and Shane Kuhlman. 2017. Assessing the unique role of religious coping in suicidal behavior among US Iraq and Afghanistan veterans. Psychology of Religion and Spirituality 9: 118-23. [CrossRef]

Durkheim, Emile. 1951. Suicide: A Study in Sociology. Translated by John A. Spaulding and George Simpson. Glencoe: Free Press. First published 1897.

Ellison, Christopher G., and Jinwoo Lee. 2010. Spiritual struggles and psychological distress: Is there a dark side of religion? Social Indicators Research 98: 501-17. [CrossRef]

Exline, Julie J., and Ephraim Rose. 2005. Religious and spiritual struggles. In Handbook of the Psychology of Religion. Edited by R. F. Paloutzian and C. L. Park. New York: Guilford, pp. 315-30.

Holmes, Thomas H., and Richard H. Rahe. 1967. The social readjustment rating scale. Journal of Psychosomatic Research 11: 213-18. [CrossRef]

Kelleher, Michael J., D. Chambers, Paul Corcoran, Esther Williamson, and Helen S. Keeley. 1998. Religious sanctions and rates of suicide worldwide. Crisis 19: 78.

Kleiman, Evan M., and Richard T. Liu. 2014. Prospective prediction of suicide in a nationally representative sample: religious attendance as a protective factor. British Joumal of Psychiatry 204: 262-66. [CrossRef] [PubMed]

Koenig, Harold G., Faten Al Zaben, and Doaa Ahmed Khalifa. 2012. Religion, spirituality and mental health in the West and the Middle East. Asian Journal of Psychiatry 5: 180-82. [CrossRef] [PubMed]

Kralovec, Karl, Sabine Kunrath, Clemens Fartacek, Eva-Maria Pichler, and Martin Plöderl. 2017. The gender-specific associations between religion/spirituality and suicide risk in a sample of Austrian psychiatric inpatients. Suicide and Life-Threatening Behavior. [CrossRef] [PubMed]

Kroenke, Kurt, Robert L. Spitzer, and Janet BW Williams. 2001. The PHQ-9: Validity of a brief depression severity measure. Journal of General Internal Medicine 16: 606-13. [CrossRef] [PubMed]

Lawrence, Ryan E., Maria A. Oquendo, and Barbara Stanley. 2016a. Religion and suicide risk: A systematic review. Archives of Suicide Research 20: 1-21. [CrossRef] [PubMed]

Lawrence, Ryan E., David Brent, J. John Mann, Ainsley K. Burke, Michael F. Grunebaum, Hanga C. Galfalvy, and Maria A. Oquendo. 2016b. Religion as a risk factor for suicide attempt and suicide ideation among depressed patients. Journal of Nervous and Mental Disease 204: 845-50. [CrossRef] [PubMed]

Liu, Richard T., and Ivan Miller. 2014. Life events and suicidal ideation and behavior: A systematic review. Clinical Psychology Review 34: 181-92. [CrossRef] [PubMed]

Neeleman, Jan, and Glyn Lewis. 1999. Suicide, religion, and socioeconomic conditions. An ecological study in 26 countries, 1990. Journal of Epidemiology \& Community Health 53: 204-10.

Neeleman, Jan, Diane Halpern, David Leon, and Glyn Lewis. 1997. Tolerance of suicide, religion and suicide rates: An ecological and individual study in 19 Western countries. Psychological Medicine 27: 1165-71. [CrossRef] [PubMed]

Nisbet, Paul A., Paul R. Duberstein, Yeates Conwell, and Larry Seidlitz. 2000. The effect of participation in religious activities on suicide versus natural death in adults 50 and older. Journal of Nervous and Mental Disease 188: 543-46. [CrossRef] [PubMed]

Nishi, Daisuke, Ryoko Susukida, Naoaki Kuroda, and Holly C. Wilcox. 2017. The association of personal importance of religion and religious service attendance with suicidal ideation by age group in the National Survey on Drug Use and Health. Psychiatry Research 255: 321-327. [CrossRef] [PubMed]

Nock, Matthew K., Guilherme Borges, Evelyn J. Bromet, Jordi Alonso, Matthias Angermeyer, Annette Beautrais, Ronny Bruffaerts, Wai Tat Chiu, Giovanni de Girolamo, Semyon Gluzman, and et al. 2008. Cross-national prevalence and risk factors for suicidal ideation, plans and attempts. British Journal of Psychiatry 192: 98-105. [CrossRef] [PubMed]

O'Reilly, Dermot, and Michael Rosato. 2015. Religion and the risk of suicide: longitudinal study of over 1 million people. British Journal of Psychiatry 206: 466-70. 
Pargament, Kenneth I., Harold G. Koenig, and Lisa M. Perez. 2000. The many methods of religious coping: Development and initial validation of the RCOPE. Journal of Clinical Psychology 56: 519-43. [CrossRef]

Paykel, Eugene Stern. 1983. Methodological aspects of life events research. Journal of Psychosomatic Research 27: 341-52. [CrossRef]

Pirkis, Jane, Dallas English, and Dianne Currier. 2013. The Australian Longituinal Study on Male Health (Ten to Men), 1st ed. Canberra: Australian Data Archive.

Pitman, Alexandra, Karolina Krysinska, David Osborn, and Michael King. 2012. Suicide in young men. Lancet 379: 2383-92. [CrossRef]

Qin, Ping, Esben Agerbo, Niels Westergård-Nielsen, Tor Eriksson, and Preben Bo Mortensen. 2000. Gender differences in risk factors for suicide in Denmark. British Journal of Psychiatry 177: 546-50. [CrossRef] [PubMed]

Rasic, Daniel T., Shay-Lee Belik, Brenda Elias, Laurence Y. Katz, Murray Enns, and Jitender Sareen. 2009. Spirituality, religion and suicidal behavior in a nationally representative sample. Journal of Affective Disorders 114: 32-40. [CrossRef] [PubMed]

Sharma, Vanshdeep, Deborah B. Marin, Harold K. Koenig, Adriana Feder, Brian M. Iacoviello, Steven M. Southwick, and Robert H. Pietrzak. 2017. Religion, spirituality, and mental health of US military veterans: Results from the National Health and Resilience in Veterans Study. Journal of Affective Disorders 217: 197-204. [CrossRef] [PubMed]

Shiner, Michael, Jonathan Scourfield, Ben Fincham, and Susanne Langer. 2009. When things fall apart: Gender and suicide across the life-course. Social Science \& Medicine 69: 738-46.

Smith, Noelle B., Natalie Mota, Jack Tsai, Lindsey Monteith, Ilan Harpaz-Rotem, Steven M. Southwick, and Robert H. Pietrzak. 2016. Nature and determinants of suicidal ideation among US veterans: Results from the national health and resilience in veterans study. Journal of Affective Disorders 197: 66-73. [CrossRef] [PubMed]

Stack, Steven, and Augustine J. Kposowa. 2011. Religion and suicide: Integrating four theories cross-nationally. In International Handbook of Suicide Prevention: Research, Policy and Practice. Edited by Rory O'Connor, Steven Platt and Jacki Gordon. London: John Wiley, pp. 235-52.

Streib, Heinz, and Constantin Klein. 2016. Religion and Spirituality. In The Oxford Handbook of the Study of Religion. Edited by Michael Stausberg and Steven Engler. Oxford: Oxford University Press, pp. 73-83.

Tarlov, Alvin R., John E. Ware, Sheldon Greenfield, Eugene C. Nelson, Edward Perrin, and Michael Zubkoff. 1989. The medical outcomes study. JAMA 262: 925-30. [CrossRef] [PubMed]

Wu, Andrew, Jing-Yu Wang, and Cun-Xian Jia. 2015. Religion and completed suicide: A meta-analysis. PLoS ONE 10: e0131715. [CrossRef] [PubMed]

(C) 2018 by the authors. Licensee MDPI, Basel, Switzerland. This article is an open access article distributed under the terms and conditions of the Creative Commons Attribution (CC BY) license (http://creativecommons.org/licenses/by/4.0/). 